\title{
Problems and Countermeasures in Hainan Province's Targeted Poverty Alleviation
}

\author{
Xu Weihong ${ }^{1, a}$, Ren Ming ${ }^{2, b}$ \\ ${ }^{1}$ School of Finance and Economics of Hainan Radio \& TV University, Haikou, Hainan Province , \\ China \\ ${ }^{2}$ Finance and Accounting Faculty of Haikou University of Economic, Haikou, Hainan Province, \\ China \\ a 1057454138@qq.com, b 50522720 @qq.com
}

Keywords: Hainan Province, Targeted poverty alleviation, performance, problems, countermeasures

\begin{abstract}
This paper analyzes the targeted poverty alleviation performance in 3 prefecture-level cities (Sansha City exclusive), 5 county-level cities, 4 counties and 6 national autonomous counties of Hainan Province, by using factor analysis and other empirical research methods, in addition to qualitative analysis, on the basis of on-the-spot investigation, consulting materials and collecting relevant data. It comes to a conclusion that 7 aspects of the work are needed to be improved, such as the construction and management of the poverty alleviation team, the meida publicity, the understanding and executing of policies. It proposes reconstruction of team, innovation of management, stimulating end ogenetic power and mobilizing its hematopoiesis, and making full use of large data to serve the precision of poverty alleviation.
\end{abstract}

\section{海南省精准扶贫绩效存在的问题及对策$$
\text { 徐卫红 }{ }^{1, a} \text { ，任明2,b }
$$ \\ 1 海南广播电视大学财经学院, 海口, 海南, 中国 \\ 2海口经济学院财务会计系, 海口, 海南, 中国 \\ a 1057454138@qq.com, b50522720@qq.com}

关键词: 海南省; 精准扶贫; 绩效问题; 对策

中文摘要.本文是在实地调研、查阅材料、收集相关数据的基础上，除进行定性分析外，还采 用因子分析法等实证研究的方法对海南省 3 个地级市（不含三沙市）、5个县级市、4个县和 6 个民族自治县的精准扶贫工作的绩效进行分析。分析了精准扶贫项目绩效方面存在问题的原 因：主要在扶贫队伍的组建与管理; 媒体宣传导向; 政策理解、执行等七大方面。提出了加 强精准扶贫队伍再建设, 创新管理方式; 通过扶志, 激发内生动力, 调动其造血功能; 让大 数据充分服务于精准扶贫等八个方面的对策建议。

\section{1. 引言}

我国提出的精准扶贫属于扶贫理论的创新，我国在扶贫的攻坚阶段开展的 “精准扶贫的 工作” 受到社会各界的关注, 从媒体的报导量、理论界文献量及相关政策、文件的出台情况 可见社会对精准扶贫工作的关注及社会整体的参与情况, 可以说是规模空前。目前对精准扶 贫的研究, 主要集中在概念、模式、机制等方面, 也有进行精准扶贫的实证研究, 学者们就 
存在的问题, 提出了许多具有价值的建议和意见。但由于扶贫是个动态的过程, 扶贫涉及的 各方面均处于不断的变化中，不同地区、不同时间针对的具体问题可能不同，这就需要我们 不断的研究精准扶贫过程中出现的新问题, 研究新对策。

\section{2. 精准扶贫绩效现状}

2015～2017年期间海南减少贫困人口46.3万人，贫困发生率由 $8.9 \%$ 降至 $1.6 \%$ 。2017年， 海南贫困地区农村居民人均可支配收入达 10321 元，同比增长 $12.5 \%$ ，比全省农民收入增速快 3.6 个百分点, 增速在全国 22 个有贫困监测的省份中排名第2位。精准扶贫取得显著成效的同 时, 也还存在许多问题。

\section{1 精准扶贫绩效统计分析结果}

从实证分析的综合因子得分排序来看：儋州市、万宁市和琼海市等三个市县（去除脱贫 任务已基本完成的海口、三亚、琼海等市县），在综合绩效中排在前三名。五指山市、白沙 县、保亭县、琼中县、乐东县和屯昌绩效综合得分排名分列倒数的后六位。从综合绩效排名 来看, 东部较为发达地区的综合绩效较好, 而绩效得分较低的市县都集中在中部地区, 说明 中部市县的精准扶贫工作需要进一步加强。

\section{2 国家巡查组对海南省精准扶贫工作成效的考核反馈}

2018年6月省扶贫开发领导小组召开会议通报国家巡查组反馈情况。国家巡查组指出: 省 委、省政府高度重视巡查整改工作, 研究出台了一批有针对性的整改措施, 整改工作取得一 定成绩, 但问题依然不少。巡查组提出海南省要以 “推进整改、精准识别、内生动力、长效 脱贫机制、政策衔接” 等5大类9个方面问题为导向，全力以赴抓好整改。

\section{3. 精准扶贫绩效存在问题的原因}

在脱贫攻坚阶段, 必须走精准扶贫之路。要取得成效实现目标, 就要精准地找到扶贫成 效不显著的原因。根据实地调研及收集相关数据的统计分析过程及结果。本研究将原因归纳 为以下几个方面。

\section{1 扶贫队伍的组建与管理方面的问题}

对扶贫一线干部配备的综合考量不够严格。有些扶贫干部对扶贫工作有负面情绪及言论、 工作的主动性不强。层层压实责任方面落实不到位。

\section{2 媒体宣传导向问题}

在扶贫成效宣传方面，媒体有大量的给贫困地区与贫困户送钱、送物作为扶贫业绩的报 导, 把这种送福利、送温暖活动宣传为让大家效仿的一种扶贫方式, 曲解了政策, 误导了扶 贫工作，影响了扶贫的绩效。

\section{3 政策理解、执行出现的问题}

有些市县出现贫困户无论上小学、大学还研究生都给补助、只要就医就不收费等情况。 盲目拔高脱贫标准，对 “两不愁、三保障” 政策存在认识上的误区。助长了贫困户等、靠、 要的思想。有些市县将 “精准扶贫” 等同于 “社会福利” 或 “慈善” 来对待。只求短期脱贫, 不考虑长远。将扶贫工作与农村的其他问题混为一谈, 农村工作都被装进扶贫工作这个大筐 中。对政策理解、执行上的问题最终导致扶贫绩效不能持续的短期化问题。 


\section{4 精准扶贫的精准度问题}

精准扶贫重在精准施策。最基础的环节是精准识别出贫困户并进行动态管理, 基础环节 出了问题就不可实现真正意义上的脱贫见效的精准。目前漏评的情况可以说已十分罕见。而 误评却较为严重。精准识别不到位有工作方法、能力的问题; 有人情关系的问题; 也有标准 不易掌握不好操作的问题; 更有数据系统不完备、不能共享等的技术问题。各环节是否真正 做到精准关键在 “人”。目前来看, 海南省的扶贫攻坚阶段在各环节均要进一步 “精准”。

\section{5 扶贫绩效评估制度有待完善}

在调查中发现, 目前海南省扶贫绩效监测体系还不成熟, 主要是因为缺乏完善的绩效管 理评价等制度。现今学者对扶贫领域的评估方法的研究众多, 但大部分研究只是侧重于某一 个方面, 缺乏全面科学系统的绩效制度和方法。也没有专业的数据库提供精准的数据, 这些 问题都给扶贫绩效评估工作带来很大的困难。

\section{6 缺少扶贫对象参与绩效评估的机制}

目前多数扶贫绩效的评价方式仍是封闭式的。大多数扶贫的绩效评估工作往往都是由相 关部门根据一些工作数据和实地考察情况对绩效进行评估。工作数据的准确性难以保障, 实 地考察总是面向少部分对象, 在这样扶贫绩效评估中, 扶贫对象参与度低, 就无法发挥自身 在绩效评估中的作用、也难以保障绩效结果取信于扶贫对象，有失科学民主化。

\section{7 扶贫信息公开不到位}

目前海南省可公开收集到的扶贫信息, 大多停留在市县一级。对于研究乡或村的问题, 只能进行实地调研, 问卷调查。实地调研覆盖面小, 很难做到对扶贫绩效的全面展示。这反 映出当前扶贫信息公开不到位, 另一方面也反映出精准扶贫政策在测评方面还不够完善。要 确保精准扶贫工作的顺利实施，就必须注重对扶贫信息的公开。

\section{4. 提高精准扶贫项目绩效的建议}

\section{1 加强精准扶贫队伍再建设, 创新管理方式}

在精准扶贫队伍再建设方面可学习借鉴四川凉山的做法：把最优兵力集结到脱贫攻坚第 一线。在管理方式方面, 层层压实责任, 把责任向扶贫一线传递。对一把手实施: “不脱贫 不调整”政策, 从而推动扶贫工作有效开展。

\section{2 通过扶志, 激发内生动力, 调动其造血功能}

\subsection{1 通过多种途径扶志}

直接有效的做法是大力宣传报导脱贫致富典型事例，增强贫困户的自信心；通过扶智达 到扶志, 采取各种形式的教育，使其扩大知识面的同时，提升自信心，树立志气。

4.2 .2 通过利益导向, 激发其内生动力

各种扶贫项目要有看得见的利益, 通过高利润, 引导贫困户自愿参与其中, 从而实现脱 贫。

\subsection{3 放弃错误的过量输血的做法, 调动其自主造血的功能}

由于建档立卡贫困户获得大量扶贫政策的好处，产生了新的不平衡，出现大家争当贫困 户的情况。在政策制定上要充分考虑, 尽可能避免上述问题的发生。也就是说制定政策也要 “精准”，要研究好村民的心理、思维及行为方式, 避免产生新的问题。 


\section{3 让大数据充分服务于精准扶贫}

建立大数据中心做好相关数据的收集。通过信息充分公开让大数据助力精准扶贫各环节, 真正实现 “扶持对象一项目安排一资金使用一措施到户一因村派人一脱贫见效” 各个环节的 精准, 并可用大数据提高扶贫绩效评价的及时性。从而提升精准扶贫的绩效。

\section{4 引导媒体做好有关扶贫的正面、正确报导}

媒体的正面、正确引导, 也是做好精准扶贫的重要一环, 有关精准扶贫的报导宣传可设 立单独审查制度。让媒体报导做到 “精准”，真正服务于精准扶贫工作。

\section{5 通过省内或跨省的移民方式, 带动贫困户从思想、行为上脱贫}

通过政策引导贫困地区的贫困户移民到相对发达地区，也可利用自然环境加政策优势引 导相对发达地区的居民批量移民到贫困地区。通过相对稳定的移居、混居, 能潜移默化地改 变贫困户的思想及行为, 突破脱贫最难关一思想、行为关。

\section{6 完善精准扶贫绩效评估制度}

有了大数据, 还需要有精准扶贫绩效评估的有效制度及方法。需要根据相关制度文件结 合海南省实际管理的需要, 建立合理的评估制度, 设计有效的评估模型, 实施动态评估, 为 管理提供实时的决策依据。在建立绩效评估制度时一定要考虑到扶贫对象的参与度, 使绩效 评估制度科学民主。

\section{7 通过精准扶贫, 真正实现各种扶贫资源的合理配置}

海南省有其特殊性，陆地面积不大，但各市县的文化却有较大差异。精准扶贫的各环节 都要关注这些差异，对各市县的贫困人口按不同标准进行分类管理、分类施策。在资金投入 方面，依据不同致贫原因和发展需求，有针对性地将资源配置在基础设施、教育、卫生等领 域。对于有能力和意愿脱贫的扶贫对象，扶贫资源要向扶贫开发的方向倾斜；对于没就业能 力没意愿的扶贫对象，扶贫资源要向培养就业能力、引导脱贫意愿方向倾斜; 对于自主发展 能力受限的扶贫对象, 则应纳入社会救济范围。在人力资本投入方面, 不仅要调动扶贫对象 的积极性, 还要全面激发农民工、大学生和退役士兵等返乡人员的创业热情和能量, 让优秀 的本地人带动、引导扶贫对象积极脱贫, 发挥人力资源在扶贫过程的关键作用。加强扶贫资 金的整合使用。加强对扶贫资金的监督管理，确保资金精准到扶贫对象。

\section{8 建立扶贫绩效动态监测机制}

扶贫工作周期长，建立对扶贫各阶段监测的机制必不可少。需要加快 “海南省精准扶贫 大数据管理平台” 建设, 建立互联互通的扶贫网络, 动态掌握贫困人口的实际需求, 做到对 扶贫全方位全过程动态监测。第一，建立对建档立卡的贫困户脱贫情况时实跟踪的机制，使 精准施策有依据。对于接受扶贫政策后实现脱贫的农户，应实施动态监测并调整扶贫范围， 防止他们挤占扶贫资源。第二，建立对扶贫项目的进展及各环节资金使用情况进行跟踪、记 录的监测机制，通过大数据进行分析，及时发现问题; 第三，建立对扶贫资金的投放与使用 绩效数据的采集、记录的机制，做到及时分析，发现问题，及时整改。

\section{5. 结束语}

现在的扶贫已不再是粗放扶贫, 而是到了啃硬骨头阶段, 这些硬骨头的主要问题在贫困 户的思想和行为上, 主要原因是内生动力不足。做好攻坚阶段的扶贫工作要靠一支强有力的 队伍, 要有全面充分的信息支持、要有媒体的正确引导和健全的制度保障, 才有可能真正做 到精确识别、精确帮扶、精确管理。也才有可能更快实现精准脱贫。 


\section{致谢}

本文为海南省社科基金一般项目《海南省精准扶贫项目绩项研究》(HNSK(JD)17-06 )的 阶段性成果之一。

\section{References}

[1] Zheng Ruiqiang and Wang Ying, Primary Exploration of Targeted Poverty Alleviation Policy, Public Finance Research, vol.396, pp. 17-24, 2016.

[2] Mo Guanghui and Chen Zhengwen, The Government Role and the Transformation Path in the Process of Poverty, Zhejiang Academic Journal, vol.01, pp. 156-163, 2017.

[3] Zhu Tianyi and Gao Lijuan, Research on the Link of Rural Governance Elite Between state and Society under the Background of Precise Poverty Alleviation--Practice Analysis XS County in Jiangxi Province, Socialism Studies, vol. 229, pp. 89-106, 2016.

[4] Yang Hao and Wang Sangui, A Study Accurately Targeting Poverty in Poverty-Stricken Areas from the Perspective of "Mass Capture", Rural Economy, vol. 07, pp. 79-83, 2016.

[5] Li Quanran, The Development of Social Assistance Policy from the Perspective of Precise Poverty Alleviation, Academic Journal of Zhongzhou, vol. 01, pp. 65-71, 2017.

[6] Sun Dechao and Bai Tian, On the Internal Mechanism and Realization Path of the Participatory Help Under the Perspective of Targeted Poverty Alleviation, Journal of Social Sciences, vol. 444, pp. 42-50, 2017. 